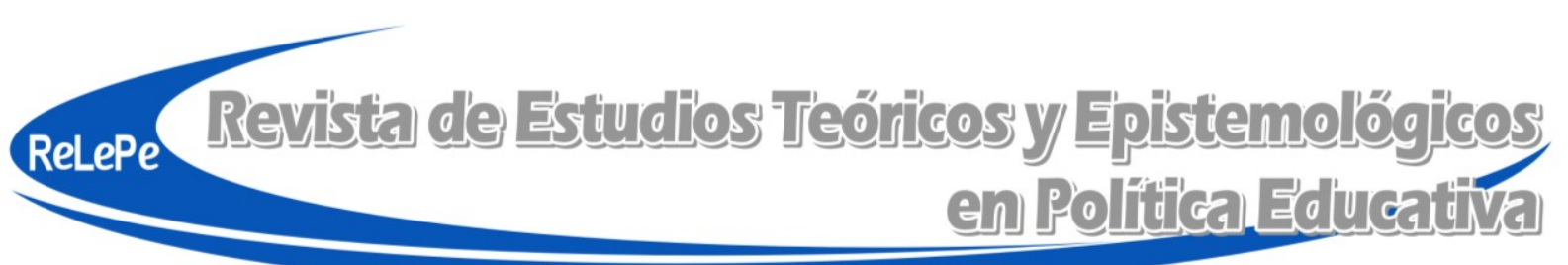

ISSN 2409-3696

DOI: $10.5212 /$ retepe.v.3.016

\title{
Apontamentos teórico-metodológicos: contribuições de Stephen J. Ball para as pesquisas de políticas educacionais
}

\author{
Mauricio de Sousa \\ Rede Municipal de Ensino de São Paulo \\ sousama@ig.com.br
}

Resumo: Este trabalho apresenta algumas contribuições teórico-metodológicas de Stephen J. Ball para a pesquisa em políticas educacionais. No decorrer do texto são analisados os seguintes conceitos: política como texto e discurso, abordagem do ciclo de políticas, teoria da atuação, novo gerencialismo e performatividade. Conclui-se que os conceitos desenvolvidos por Ball, em análise do cenário educacional inglês e europeu, também podem contribuir para as pesquisas de políticas educacionais brasileiras, em especial, aquelas voltadas para a política de avaliação externa em larga escala.

Palavras-chave: Stephen J. Ball. Política educacional. Análises de políticas.

Theoretical-methodological notes: Stephen J. Ball's contributions for education policies research

Abstract: This paper presents some theoretical-methodological contributions by Stephen J. Ball for educational policy research. Throughout the text the following concepts are analyzed: politics as text and discourse, policy cycle approach, theory of enactment, new managerialism and performativity. It is concluded that such concepts developed by Ball, when analyzing the British and European scenarios, can contribute to the research of Brazilian educational policy, especially those focused on the policy in large scale external evaluation.

Keywords: Stephen J. Ball. Education policy. Policies analysis.

\section{Apuntes teórico-metodológicos: contribuciones de Stephen J. Ball para las investigaciones de políticas educativas}

Resumen: Este trabajo presenta algunas contribuciones teórico-metodológicas de Stephen J. Ball para la investigación en políticas educativas. Al transcurrir del texto se analizan los siguientes conceptos: política como texto y discurso, abordaje del ciclo de políticas, teoría de la actuación, nuevo gerencialismo y performactividad. Se concluye que los conceptos desarrollados por Ball, en análisis del escenario educativo inglés y europeo, también pueden contribuir con las investigaciones de políticas educativas brasileñas, en especial, aquellas dirigidas para la política de evaluación externa a gran escala.

Palabras clave: Stephen J. Ball. Política educativa. Análisis de políticas. 


\section{Introdução}

Stephen J. Ball é professor do Instituto de Educação da Universidade de Londres, no qual ocupa a cátedra Karl Mannheim, e tem diversos estudos sobre a política educacional, abordando temas como: globalização, neoliberalismo, mercantilização da educação, redes de políticas, etc. Os seus estudos têm influenciado e contribuído para as pesquisas sobre políticas educacionais por todo mundo. Neste texto são recuperadas algumas de suas contribuições para o campo teórico e metodológico, como: a política como texto e discurso, a abordagem do ciclo de políticas, a teoria da atuação, novo gerencialismo e performatividade. Como isso, cada seção deste texto descreve cada uma destas temáticas teórico-metodológicas e como podem contribuir para a análise das políticas educacionais brasileira, principalmente, as políticas de avaliação em larga escala.

\section{A política como texto e discurso}

Stephen J. Ball diz que um dos problemas dos estudos sobre as políticas ${ }^{1}$ é a sua própria conceituação, ou seja, muitos "analistas não conseguem definir o que a política significa conceitualmente" (BALL, 2002a, p. 20), e continua afirmando, nesse artigo, que "não é difícil achar que o termo é usado para descrever coisas muito diferentes em diferentes pontos do mesmo estudo" (BALL, 2002a, p. 20). Para Ball, não se pode compreender o termo política de forma linear, estática e superficial, proporcionando a definição reduzida da política:

[...] como uma tentativa de "resolver um problema". Geralmente, essa resolução de problema é feita por meio da produção de textos de políticas como legislações ou outras prescrições e inserções voltadas local ou nacionalmente à prática. Esse tipo de análise política "normativa", em geral, "assume" a política como uma preservação do aparato formal do governo de formulação de políticas ou como a única resposta plausível para [as] mudanças sociais e econômicas do Estado. O problema é que, se a política só é vista nesses termos, então todos os outros momentos dos processos de política e atuação das políticas que acontecem dentro e em torno das escolas são marginalizados ou passam despercebidos (BALL; MAGUIRE; BRAUN, 2016, p. 13).

Isso significa que, para Ball, as pesquisas sobre as políticas devem ir além da clássica construção analítica: formulação, implementação e avaliação (FREY, 2000; SERAFIM; DIAS, 2012). Como também entender que todo esse processo de estabelecimento das políticas não se restringe ao controle do Estado ${ }^{2}$. Portanto, as políticas são constituídas em um campo que envolve diferentes contextos e atores, em constantes disputas, como diz Ball, em entrevista:

\footnotetext{
1 Utiliza-se o termo "políticas", no plural, assim como Ball, que compreende que a política se estabelece em um campo de disputa. Em muitos momentos, haverá diferentes discursos políticos, por vezes conflitantes, contraditórios, no mesmo tempo e espaço. Dessa forma, pode-se pensar em políticas e não apenas em uma única política.

2 Não é objetivo deste trabalho discutir o conceito de Estado. Não obstante, não significa que se desconsidera o papel do Estado na formulação de políticas, mas que se compartilha com outros autores que a análise das políticas públicas não deve ficar centralizada apenas no Estado, como escreve Serafim e Dias (2012, p. 124), fundamentados nas ideias de Ozlak: “[...] o Estado é aquilo que se faz, afirma Oszlak, ou seja, o Estado que temos hoje é produto da sobreposição das numerosas agendas que foram sendo construídas, negociadas, modificadas ou mesmo descartadas ao longo da história”. Desta forma, existem diferentes abordagens para o estudo das políticas públicas, como apontadas nos estudos de Frey (2000); Lessard; Carpentier (2016); Tello; Mainardes (2012).
} 
[...] eu penso que a maioria das análises de políticas é dominada por um pressuposto implícito, não discutido, de racionalidade, de que os processos de políticas são racionais, de que é um processo ordenado, coerente. [...] e muito do trabalho em política não é lá muito racional, ordenado nem muito bem organizado. Por isso, temos de pensar teoricamente sobre a possibilidade de irracionalidade, de confusão, de desordem, de caos (MAINARDES, 2015, p. 161-162).

A "superação" dessa visão estática e racional da política, em especial, no sentido de que vai além da normatização e da ação do Estado, ocorre porque, para Ball (2002a), as políticas são estabelecidas em arenas de disputas sociais, econômicas, ideológicas, etc. O discurso político, por algum momento, torna-se hegemônico, mas estará sempre em disputas com outros discursos que ocorrem nessas arenas. Trata-se de uma sociologia da ação pública, como descrevem Lessard e Carpentier (2016, p. 91):

[...] rompe com o mito da ação pública racional e desinteressada. Portanto, existem sistemas de agentes dentro e fora do Estado, cujos interesses, ideias e comportamento estratégico é importante compreender e explicar. Esses sistemas de agentes e suas interações permitem descrever trajetórias de políticas e narrativas de políticas (policy narratives), momentos mais ou menos vinculados, cada um com seu contexto, os problemas identificados e as soluções propostas.

Ao mesmo tempo, a compreensão de que os sujeitos envolvidos nesses processos não são meros "implementadores" e, ao contrário, realizam processos de interpretação e de tradução ${ }^{3}$, que resultam em diferentes políticas dentro de um mesmo espaço. São essas as características que ocorrem nos processos de estabelecimentos de políticas, visto que Ball (2002a, p. 20) entende a política como texto e discurso, sempre destacando que "[...] a política não é uma ou outra, mas ambas".

A política como texto é materializada em documentos, legislações, atas, publicações, etc. Todavia, esses textos têm uma pluralidade de leitores, que resultam em diversos significados, mesmo quando "os formuladores de políticas fazem os esforços necessários para afirmar tal controle com os meios disponíveis e obter uma leitura correta" (BALL, 2002a, p. 21). Entretanto, esses textos de políticas, no campo educacional, muitas vezes, são confusos ou pensados para "escolas ideais, perfeitas", que muitas vezes não existem no contexto em que foram produzidos (BALL; MAGUIRE; BRAUN, 2016). Isso significa entender que os textos de políticas:

São o produto de compromissos em várias etapas (no momento da influência inicial na micropolítica da formulação legislativa, no processo parlamentar e nas políticas e micropolíticas dos grupos de interesse). Eles são tipicamente produtos canibalizados de múltiplas (mas circunscritas) influências e agências. Há ações não planejadas, negociação e oportunismo dentro do Estado e dentro do processo de formulação da política (BALL, 2002a, p. 21).

O texto político representa uma disputa de poder, no sentido de que há uma competição entre os diferentes textos (ou discursos políticos), de acordo com os grupos de interesse, para que um texto seja constituído como "vencedor" ou "hegemônico". E mesmo constituído, esse texto passa por diversas leituras, assim, por exemplo, a mudança de um chefe ou secretário de Estado

\footnotetext{
${ }^{3}$ No livro: Como as Escolas Fazem as Políticas: Atuação em Escolas Secundárias, os autores Ball, Maguire e Braun (2016, p. 69) explicitam melhor o conceito de interpretação e de tradução das políticas. A interpretação é uma decodificação da política, "um processo de explicação, esclarecimento e criação de uma agenda institucional [...] envolve vender a política para a equipe". Já a tradução "é um processo interativo de fazer textos institucionais e colocar esses textos em ação, literalmente 'atuar' sobre a política” (BALL; MAGUIRE; BRAUN, 2016, p. 69).
} 
pode resultar em nova interpretação. Da mesma forma, no contexto escolar, esses textos sofrem novas interpretações e traduções, isso porque:

As políticas geralmente não dizem o que fazer, elas criam as circunstâncias nas quais o leque de opções disponíveis para dizer são metas ou resultados restritos, em mudança ou específicos são definidos. No entanto, uma resposta deve ser armada, construída em contexto e contrabalançada com outras expectativas. Tudo isso envolve uma ação social criativa, não uma reação robótica (BALL, 2002a, p. 24).

Existe, assim, um campo de atuação de diferentes atores na política (BALL; MAGUIRE; BRAUN, 2016), por isso, não se pode dizer que todas as políticas são aplicadas da mesma forma como foram pensadas por seus formuladores. Isso significa que os atores envolvidos nessas políticas são capazes de fazer suas interpretações e traduções (aceitando, negando ou resistindo).

Essa premissa sobre a atuação dos atores já vinha sendo desenvolvida por Ball, em conjunto com Bowe e Gold (1992), nos anos 1990, utilizando-se da teoria literária de Roland Barthes, o que possibilitou aos autores compreenderem que os textos políticos podem ser pesquisados, a partir de dois elementos: readerly, ou leitura direta, literal dos textos políticos. Por exemplo, na legislação sobre uma avaliação externa em larga escala, encontra-se, nessa normativa, os objetivos; a quem será aplicada; como e quando será aplicada; como serão oferecidos os resultados; quem serão os aplicadores; as disciplinas que serão avaliadas; etc. Portanto, não existe margem para interpretação, pois se tem que cumprir o que está determinado na normativa. Entretanto, após a aplicação dessa avaliação externa, em larga escala, são apresentados novos textos com os resultados e suas interpretações. Esses textos "convidam" o leitor a fazer as suas interpretações, análises, etc., ou seja, não se trata de um texto "fechado", e aqui se tem o writerly, segundo elemento do texto. Dessa forma, os textos políticos:

Enquanto a construção do texto da política pode envolver diferentes partes e processos para o processo de "implementação", a oportunidade de reformar e reinterpretar o texto significa que a formação de políticas não termina com o "momento" legislativo; "Para qualquer texto, uma pluralidade de leitores deve necessariamente produzir uma pluralidade de leituras" (BOWE; BALL; GOLD, 1992 , p. 25, grifos do autor).

Essa pluralidade de leitores e de leituras, de interpretações e de traduções, por parte dos atores envolvidos, significa que a política ocorre em um campo de disputas, e estas caracterizam os discursos, ou seja, a política como discurso. Ball (2002a, p. 26) fundamenta-se em Foucault, para definir o que é discurso, caracterizado desta maneira:

Os discursos são sobre o que pode ser dito e pensado, mas também sobre quem, quando, onde e com que autoridade pode falar. Os discursos incorporam significados e usam proposições e palavras. Desta forma, certas possibilidades de pensamento são construídas. As palavras são organizadas e combinadas de uma maneira particular, removendo ou excluindo outras combinações.

Isso significa que o estudo das políticas educacionais, neste caso, deve atentar-se: quais discursos são difundidos? Por quem? Para quem? Dessa forma, ao serem analisadas as políticas educacionais, nas últimas décadas, desde o final do século XX, observa-se a difusão de discursos de caráter economista e mercadológico (BALL; YOUDELL, 2007; GENTILI; SILVA, 2001; SILVA, 2009), defendendo elementos empresariais, como: eficiência, produtividade, meritocracia para melhoria da qualidade da educação. 
A partir desses discursos, como exemplo, os de viés econômico/mercadológico são os "[...] que marcam o direcionamento da política; que circulam, reforçam e representam o que deve ser feito" (BALL; MAGUIRE; BRAUN, 2016, p. 171). A política, portanto, é materializada. Nesse exemplo, alguns organismos ou instituições (CHARLOT, 2007), defendem que, para a melhoria da qualidade da educação pública, é necessário adotar as seguintes práticas: currículo único e prescritivo, monitoramento via avaliação externa, e políticas de meritocracia para bonificação de professores e de gestores. Em contrapartida, existem os discursos de contestação, de resistência e de negação, que não podem ser negados nos momentos das análises de políticas, pois "[...] a tarefa do pesquisador de políticas é encontrar como o ser humano é visto em nosso presente e as práticas sociais que constituem este ser humano" (BALL, 2015, p. 308).

Ball ressalta, em uma de suas entrevistas que, para pensar a política como discurso é preciso que sejam tomados alguns cuidados, em sua análise.

Eu queria pensar sobre interpretação e discurso, eu queria tentar pensar sobre a diferença entre posicionar o sujeito no centro do significado como um ator interpretativo, alguém que é um interpretador ativo, tradutor ativo do mundo social. Em oposição a uma visão dele como um sujeito produzido pelo discurso, que é "falado" pelo discurso, ao invés de um locutor do discurso. [...] queria tentar levar analistas de políticas a serem mais claros sobre se vemos estes atores em algum momento como interpretadores ativos do mundo, que estão criando significado, ou se são produtos de discurso (AVELAR, 2016, p. 6, grifos do autor).

Isso significa pensar que a construção do discurso em políticas não ocorre apenas externamente ao sujeito, como mero produto dos discursos, mas que os atores envolvidos também são locutores de discursos e são capazes de os construírem. Partindo desse enfoque, Ball faz uma crítica às análises políticas que se detém apenas no sujeito como implementador de políticas, sendo incapaz de repensá-la, seja para aceitar, modificar, negar ou resistir. É claro que essa capacidade criativa dos atores, como aponta Ball, nessa mesma entrevista, ressalta que as políticas "[...] ao menos em parte, são construídas em outros lugares, dentro do discurso" (AVELAR, 2016, p. 6).

Nesse sentido, a construção do discurso na política não:

[...] é irredutível à linguagem e à fala, é mais que isso. Nós não falamos, ele fala para nós. Somos as subjetividades, as vozes, o conhecimento, as relações de poder que o discurso constrói e permite. Nós não sabemos o que dizemos, somos o que dizemos e fazemos. Nestes termos, a política fala através de nós, assumimos as posições construídas por nós mesmos dentro da política. Este é um sistema de práticas (marketing dos nossos cursos, promoção da nossa instituição) e um conjunto de valores e ética (forçando os colegas improdutivos a se aposentarem cedo para que não sejam levados em conta no orçamento do departamento). Os discursos conseguem que as coisas sejam feitas, que as tarefas reais sejam realizadas, acumulam autoridade. (BALL, 2002a, p. 27, grifos nossos).

Dessa forma, pensar a política como discurso possibilita entender que os atores constroem seus discursos e permitem também conhecer o próprio sujeito, as subjetividades, os valores. Para Ball, recorrendo a Foucault, pensar a política como discurso significa pensar "[...] como os discursos são construídos e como eles mudam, mas também como eles moldam todos os dias da existência, isto é, em parte, pelo menos, como eles 'formam os objetos de que falam"' (BALL, 2015, p. 307, grifos do autor). Desta forma, para Ball (2002a), as políticas estabelecidas pelo Estado são compostas por discursos (dos atores envolvidos, das instituições, das 
organizações, etc.) e, ao mesmo tempo, podem ser reconfiguradas por novos discursos, ou interpretadas de maneiras diferentes pelos sujeitos, que não apenas são moldados pelos discursos, mas também têm seus próprios discursos, ou seja, em certa medida "[...] não fazemos política, a política nos faz" (BALL, 2015, p. 307).

Nesse processo de análise, para Ball (2015, p. 307), o discurso é materializado em “[...] objetos políticos (artefatos), arquiteturas, subjetividades e práticas. Estes são os instrumentos e efeitos do discurso". Como exemplo, pode-se entender que, em uma política como a atual, de viés neoliberal ${ }^{4}$, se têm novos rearranjos (arquiteturas) do papel do Estado, que passa a assumir uma posição de avaliador (AFONSO, 2009), para garantir esse papel de fiscalização e de controle.

Um dos mecanismos utilizados no campo educacional é a adoção de um sistema de avalição externa para que sejam estabelecidas competições entre as escolas, as metas, rankings, etc. Com isso, cria-se uma série de artefatos como: softwares para verificação do desempenho dos estudantes; ranqueamento das escolas para divulgação dentro e fora das unidades escolares, etc.

Em outra ponta, podem ser estabelecidas novas práticas, no contexto da escola, como: treinar os alunos para a prova; focar apenas nas disciplinas que serão avaliadas; estabelecer um currículo mínimo e prescritivo; etc. Por fim, como um dos efeitos dessa política, o que Ball (2002b) chama de "os terrores da performatividade" acaba afetando a própria subjetividade do que é ser professor e qual o seu papel. Isso significa a redução do papel do professor a apenas desenvolver as "competências", que serão cobradas dos estudantes nessas avaliações.

Diante da política antes descrita, é possível pensar que não existem mais alternativas ou outros caminhos, mesmo sabendo que alguns discursos acabam sendo hegemônicos por algum tempo. Por isso, a compreensão da política como discurso possibilita compreender que:

[...] na prática, em sociedades modernas complexas, estamos enredados numa variedade de discursos discordantes, incoerentes e contraditórios, e o conhecimento subjugado não pode ser totalmente excluído da arena da implementação de políticas (BALL, 2002a, p. 28).

No entanto, Ball (2002a, p. 28) deixa claro, que o discurso neoliberal, neste momento atual (ou melhor, desde os anos 1980), ainda é predominante "[...] mas precisamos reconhecer e analisar a existência de 'discursos' dominantes, regimes de verdade, conhecimento acadêmico como o neoliberalismo e a teoria da administração - dentro da política social”. Entretanto, mesmo com o discurso neoliberal dominante, existem campos de disputa em que este pode ser colocado em xeque, como mesmo afirma Ball, em uma entrevista: "as políticas desaparecessem no decorrer do tempo ou, algumas vezes, leva muito tempo para elas se tornarem integradas. Algumas vezes, elas são apressadas ou atrasadas" (MAINARDES; MARCONDES, 2009, p. 307).

\footnotetext{
${ }^{4}$ Para Ball et. al. (2013, p. 25), o termo neoliberalismo é tão alargado que se torna, às vezes, sem sentido. Para definir neoliberalismo, recorre às ideias de Ronen Shamir, professor de sociologia da Universidade de Tel Aviv, que diz o seguinte: "é tratado nem como uma doutrina econômica concreta nem como um conjunto definido de projetos políticos. Pelo contrário, eu trato neoliberalismo como um conjunto complexo, muitas vezes incoerente, instável e até mesmo contraditório de práticas que são organizadas em torno de certa imaginação do 'mercado' como base para 'a universalização das relações sociais baseadas no mercado, com a correspondente penetração em quase todos os aspectos de nossas vidas, do discurso e/ou da prática de mercantilização, de acumulação, de capital e de geração de lucros"”. Isto é, a política neoliberal envolve tanto as relações materiais como as sociais.
} 


\section{A abordagem do ciclo de políticas (policy cycle approach)}

Para compreender esses campos de disputa no estabelecimento das políticas, no tempo e no espaço, recorre-se à abordagem do ciclo de políticas (policy gycle approach), também desenvolvida por Ball e seus colaboradores Bowe e Gold, nos anos 1990. No livro Reforming Education and Changing Schools: Case Studies in Policy Sociology (1992) são apresentados os primeiros contextos de análise da trajetória da política ${ }^{5}$ : contexto de influência, contexto de produção do texto político e do contexto da prática. Posteriormente, no livro Education Reform: A Critical and Post-structural Approach (1994), Ball amplia a sua análise da trajetória política, explicitando os contextos dos resultados e da estratégia política.

Antes de apresentar as características de cada contexto, entende-se ser necessário esclarecer que a abordagem do ciclo de políticas, realizada por Ball, busca pensar a política em uma perspectiva diferente do processo de formulação, de implementação e de avaliação, pois, como o autor afirma: "[...] eu não acredito que políticas sejam implementadas, pois sugere um processo linear pelo qual elas se movimentam em direção à prática de maneira direta" (MAINARDES; MARCONDES, 2009, p. 305). Da mesma forma que não existe linearidade nos ciclos de políticas ${ }^{6}$, e dentro de um mesmo contexto, existem espaços de disputas, como explica Ball (MAINARDES, MARCONDES, 2009, p. 306-307):

Os contextos podem ser pensados de outra maneira e podem ser "alinhados" uns dentro dos outros. Assim, dentro do contexto de prática, você poderia ter um contexto de influência e um contexto de produção de texto, de tal forma que o contexto de influência dentro do contexto da prática estaria em relação à versão privilegiada das políticas ou da versão privilegiada da atuação. Assim, podem existir disputas ou versões em competição dentro do contexto da prática, em diferentes interpretações de interpretações. E, ainda, pode haver um contexto de produção de texto dentro do contexto de prática, na medida em que materiais práticos são produzidos para utilização dentro da atuação. Assim, podem existir espaços dentro de espaços. Podemos refletir a respeito das políticas em termos de espaços e em termos de tempo, de trajetórias políticas, movimentos de políticas através do tempo e de uma variedade de espaços. Uma política tem uma trajetória semelhante à de um foguete: decola, atravessa o espaço e depois aterrissa. Algumas vezes, acidenta-se; em outras, atinge uma realização espetacular, mas move-se através do tempo e, algumas vezes, simplesmente desaparece. (grifo do autor).

Portanto, a abordagem do ciclo de políticas busca compreender "como estas políticas são feitas" (AVELAR, 2016; MAINARDES; MARCONDES, 2009), isto é, os discursos são rediscutidos, realinhados, redefinidos e apropriados pelos atores envolvidos naquele momento e tempo. Feitas essas ressalvas, passa-se a descrever cada um dos contextos da trajetória política.

\footnotetext{
${ }^{5}$ Essa ideia da trajetória da política foi mais esclarecida na entrevista que Ball concedeu à pesquisadora Marina Avellar (2016, p. 6) em que diz: “[...] Nós estávamos pensando sobre política e tentando criar uma ideia de trajetória da política. Tentando pensar na política não como documento, ou uma coisa, mas sim uma entidade social que se move no espaço e o modifica enquanto se move, e modifica coisas nesse movimento, modifica o espaço pelo qual se move. Então ela é mudada por coisas e muda coisas".

${ }^{6}$ Para Oliveira e Lopes (2011, p. 22), Ball mantém em suas análises o par dicotômico formulação-implementação, pois este "mantém a ideia de que as políticas têm origem no contexto de influência, capaz da proposição de ações políticas que modifiquem ou mantenham determinadas finalidades, bem como mantém uma relação determinista de avaliação de políticas, conectada à consecução de finalidades na prática". Continuando sua crítica, entendem que esta abordagem acaba reforçando as análises estadocêntricas, isto porque esta abordagem "reforça a concepção de um Estado ou de uma instituição a quem compete elaborar estratégias no sentido de garantir as finalidades de sua agenda política e de um contexto a quem compete avaliar seus resultados com relação à implementação dessa agenda, circunscrito ao contexto da prática" (OLIVEIRA; LOPES, 2011, p. 22-23).
} 
O contexto de influência é assim caracterizado por Bowe, Ball e Gold (1992, p. 19-20):

O primeiro contexto, o contexto de influência, é onde a política pública é geralmente iniciada. É aqui que os discursos políticos são construídos. É aqui que as partes interessadas lutam para influenciar a definição e os propósitos sociais da educação, o que é ser educado. As arenas privadas de influência são baseadas nas redes sociais dentro e ao redor dos partidos políticos, dentro e ao redor do governo e em todo o processo legislativo. Aqui os principais conceitos políticos são estabelecidos (por exemplo, forças de mercado, currículo nacional, exclusão, devolução orçamentária), eles adquirem moeda e credibilidade e fornecem um discurso e um léxico para a iniciação da política.

No contexto de influência, portanto, todos os discursos sobre uma temática são apresentados e colocados em disputa. Assim, nesse contexto, tem-se a influência não apenas de grupos, de atores e de instituições locais, mas também de organismos e de instituições estrangeiras, que também influenciaram na trajetória política. Atualmente, no campo educacional, mas de forma mais massiva, desde os anos de 1990, existem discursos advindos de instituições internacionais, como o Banco Mundial (BM) e a Organização para a Cooperação e Desenvolvimento Econômico (OCDE), por meio da difusão de concepções de qualidade baseadas no desempenho de alunos participantes de avaliações externas em larga escala, como o Programa Internacional de Avaliação de Alunos (PISA). Na mesma direção, atualmente, no Brasil existe uma série de institutos e fundações, como a Fundação Lemman, o Instituto Ayrton Senna, o Movimento Todos pela Educação, etc, (ADRIÃO; PERONI, 2011; MARTINS, 2013), que têm apresentado uma série de pautas, de encaminhamentos para a educação pública do País, e aqui cabe a crítica, como a estabelecida por Ball em uma de suas entrevistas:

[...] ninguém os elegeu, eles não possuem nenhuma autoridade, eles não possuem legitimidade política de nenhum tipo, o que eles têm é muito, muito, muito dinheiro. E eles são capazes de usar este dinheiro para causar mudança na política educacional, e aplicar suas ideias (AVELAR, 2016, p. 11).

Isso significa que, atualmente, no contexto de influência, encontram-se cada vez mais marcantes discursos políticos sobre a educação pública, com viés mercadológico e economicista. $\mathrm{E}$ esses discursos têm se materializado em políticas, com a venda de programas de gestão educacional; material apostilado; formação de professores; etc., para diversos Estados e municípios brasileiros. Difundindo as concepções gerencialista e da performatividade, como descritas em algumas pesquisas, como, por exemplo, sobre o município paulista de Campinas (OLIVEIRA, 2016), e dos Estados de Goiás e Mato Grosso (GAWRYSZEWSKI; MOTTA; PUTZKE, 2017).

No contexto de produção, encontra-se a materialização da política, por meio de documentos legais, de textos políticos, de comentários, etc. Esse contexto está intrinsecamente ligado ao anterior, e ambos são produzidos quase ao mesmo tempo, pois as diferentes disputas no campo da influência vão ser materializadas em textos da política. Nesse contexto, Ball destaca que os textos de política não terminam no momento em que são produzidos, pois não são claros e necessitam de novas leituras (como apontado anteriormente na questão writerly). 
[...] A política não é feita e terminada no momento legislativo, evolui nos e através dos textos que a representam, os textos têm que ser lidos em relação ao tempo e ao local particular de sua produção. Eles também precisam ser lidos com e contra os outros - a intertextualidade é importante. Em segundo lugar, os textos em si são o resultado da luta e do compromisso. O controle da representação da política é problemático. Controle sobre o momento da publicação dos textos é importante. [...] Grupos de atores que trabalham em diferentes locais de produção de texto estão competindo pelo controle da representação da política. A maioria dessas lutas acontece a portas fechadas, mas vislumbres ocasionais da dinâmica do conflito são possíveis. O que está em jogo são tentativas de controlar o significado da política por meio de sua representação. As políticas, então, são intervenções textuais, mas também carregam consigo restrições e possibilidades materiais. As respostas a esses textos têm consequências reais (BOWE; BALL; GOLD, 1992, p. 21).

Essas consequências reais são as interpretações que o texto político recebe na prática, como é exemplo da legislação, que possibilita diferentes interpretações, de acordo com a leitura que um grupo faz. São essas leituras e interpretações que caracterizam o contexto da prática. Essa disputa ocorre na maneira como são compreendidos esses textos e as consequências reais, geradas a partir daí. Por isso que, para Ball, as políticas não são meramente implementadas e o ator político também faz parte da trajetória de construção delas, isto é, as políticas não se encerram no espaço macro, quando são transformadas em textos políticos, como as legislações ou normativas educacionais, também se estendem para o espaço micro, como a sala de aula, local em que o professor faz suas interpretações e traduções (BALL; MAGUIRE; BRAUN, 2016). Isso significa pensar que:

[...] os praticantes não confrontam os textos de políticas como leitores ingênuos, eles vêm com histórias, com experiência, com valores e propósitos próprios, eles têm interesses no significado da política. As políticas serão interpretadas de forma diferente, à medida que as histórias, experiências, valores, propósitos e interesses que compõem as diferentes arenas. O ponto simples é que os formuladores de políticas não podem controlar os significados de seus textos. Partes de textos serão rejeitadas, selecionadas de forma ignorada, deliberadamente mal compreendidas, respostas podem ser frívolas, etc. Além disso, mais uma vez, a interpretação é uma questão de luta. Diferentes interpretações entrarão em competição, referem-se a diferentes interesses, uma ou outra interpretação vai predominar (BOWE; BALL; GOLD, 1992, p. 2223).

Nessa abordagem do ciclo de políticas, em conjunto com a teoria da atuação, fica difícil prever os efeitos de uma política, porque não se relacionam apenas à capacidade de controle por seus formuladores. Nesse ponto, todos os atores envolvidos "no fazer da política", no "colocálas em práticas", podem efetivar as suas interpretações (rejeitando, anulando, aceitando parcialmente, etc.). Essas interpretações resultam de histórias, de interesses, de valores, etc., que cada ator político carrega dentro de si, ou seja, existe uma subjetividade da política, que não pode ser controlada, por mais que se deseje.

Já no início dos anos de 1990, Ball e seus colaboradores já mencionavam os efeitos da política, e esses serão mais bem definidos, em 1994, no livro Education Reform: A Critical and Poststructural Approach, em que são conceituados o contexto dos resultados ou efeitos e contexto de estratégia política. Para o contexto dos resultados ou efeitos, Ball (1994, p. 24) estabelece que os efeitos de primeira e de segunda ordens são: 
[...] uma outra distinção importante a ser feita em relação aos efeitos, uma distinção entre o que pode ser chamado de efeitos de primeira ordem e de segunda ordem. Os efeitos de primeira ordem são mudanças na prática ou estrutura (que são evidentes em locais específicos e em todo o sistema como um todo), e os efeitos de segunda ordem são o impacto dessas mudanças nos padrões de acesso social, oportunidade e justiça social.

Como exemplo desses efeitos da política, pode-se pensar nos sistemas de avaliação externa, controlados pelo Estado e, como efeito de primeira ordem, podem ser elencados os diferentes impactos no currículo, nas práticas em sala de aula, na subjetividade do professor, etc. Entretanto, até que ponto essas políticas conduzem a uma melhoria da oportunidade de justiça social? Será que reforçam a desigualdades entre os estudantes? Será que reforçam os conceitos de "boas" ou "más" escolas ou de "bons" ou "maus" professores? Ou seja, esses sistemas de avaliação externa, em sua maioria, têm produzido efeitos, mas não em oposição às desigualdades sociais e à justiça social (segunda ordem), e sim valorizando a individualidade e a competitividade.

Nesse sentido, o contexto de estratégia política visa, justamente, "[...] a identificação de um conjunto de atividades políticas e sociais que possam mais eficazmente combater as desigualdades" (BALL, 1994, p. 26). Ainda Ball, ancorado por Foucault, diz que esta seria uma tarefa do pesquisador de políticas públicas: "[...] criticar o funcionamento de institutos que parecem ser neutros e independentes, tal maneira que a violência política que sempre se exerceram obscuramente seja desmascarada, e, que assim possamos combatê-los" (BALL, 1994, p. 27).

\section{Teoria da atuação}

A teoria da atuação (policy enactment) ${ }^{7}$ desenvolvida por Ball e seus colaboradores no livro How school do policy (2012) e traduzida para o Brasil com o título Como as Escolas Fazem Políticas: Atuação em Escolas Secundárias (2016), já vinha sendo construída por Ball desde os anos de 1990, em especial, quando descreve o contexto da prática na abordagem do ciclo de políticas e as análises dos contexto da prática (MAINARDES; GANDIN, 2013a, 2013b; MAINARDES; STREMEL, 2015; MAINARDES, 2006; 2018; PAVEZI, 2018; LIMA; SOUZA; LUCE, 2018; ROSA, 2019; HOSTINS; ROCHADEL, 2019).

Justamente no contexto da prática que a política é colocada em ação (e não apenas implementada) de diferentes maneiras, pois em cada contexto essa política (ação) demanda diferentes repostas. Nesse sentido, os gestores, os professores e os demais funcionários não são meros implementadores da política educacional, ao contrário, eles atuam, reinterpretam, reconfiguram essas políticas de forma mais ou menos criativa, o contexto é que define o processo de atuação. Esse processo, então, é entendido como o espaço de:

\footnotetext{
${ }^{7} \mathrm{Na}$ obra Como as escolas fazem políticas: atuação em escolas secundárias, Ball, Maguire e Braun (2016, p. 12) desenvolvem a teoria da atuação (policy enactment) política que, segundo os revisores da obra para a língua portuguesa, esse termo é utilizado "no sentido teatral, referindo à noção de que o ator possui um texto que pode ser apresentado/representado de diferentes formas". O texto, no entanto, é apenas uma parte (porém, uma parte importante) da produção. Os autores usam esse termo para indicar que as políticas são interpretadas e materializadas de diferentes e variadas formas. Os atores envolvidos (no caso, os professores) têm o controle do processo e não são "meros implementadores". Ver Joslin (2017); Marcondes; Freund; Leite (2017); Mainardes (2018); Pavezi (2018).
} 
[...] atuação de política como um aspecto dinâmico e não-linear de todo o complexo que compõe o processo da política, do qual a política é apenas uma parte. Políticas "começam" em pontos diferentes e têm diferentes trajetórias e expectativas de vida; algumas são obrigatórias, outras fortemente recomendadas ou sugeridas. Algumas políticas são formuladas "acima" e outras são produzidas nas escolas ou pelas autoridades locais, ou simplesmente tornam-se abordagens da "moda" na prática sem um início claro (BALL, MAGUIRE, BRAUN, 2016, p. 18-19, grifos dos autores).

Isto quer dizer que Ball e seus colaboradores "concebem as políticas como um processo, como algo que se move, que acontece em meio a interações e em terrenos instáveis" (ROSA, 2019 , p. 7) e essas políticas não se restringem apenas às legislações ou suas normatizações. Tais políticas também são encenadas, estão presentes nos corpos, nas ações, nos espaços daqueles que as transformam e as reinterpretam.

Para a compreensão da atuação dos diferentes atores da política educacional, os contextos têm que serem levados a sério (BALL, MAGUIRE, BRAUN, 2016). E esses contextos são caracterizados: Contextos situados - são abordados aspectos ligados a escola, como matrículas, localização, história, etc.; Culturas profissionais - que são os valores e o envolvimento dos professores em determinada escola; Contextos materiais - são os aspectos físicos da escola; Contextos externos - são as pressões que a escola sofre, em virtude das políticas, como, por exemplo, as políticas de avaliações externas em larga escala, em que a pressão por melhores resultados acaba refletindo nas atuações políticas dos atores, na escola.

A intersecção destes contextos interfere no processo de atuação dos diferentes atores nos processos de interpretação da política que é a decodificação da política "[...] um processo de explicação, esclarecimento e criação de uma agenda institucional" (BALL, MAGUIRE, BRAUN, 2016, p. 69). Este processo de interpretação, normalmente, é realizado por diretores, coordenadores, supervisores, nos espaços escolares. E de tradução da política "é um processo interativo de fazer textos institucionais e colocar esses textos em ação, literalmente "atuar" sobre a política” (BALL, MAGUIRE, BRAUN, 2016, p. 69), que é como exemplo como o professor, no espaço da sala de aula, traduz uma política curricular em procedimentos, conceitos didáticos.

A teoria da atuação, em um aspecto metodológico, contribui “[...] para a coleta de dados no contexto da prática, bem como para a análise dos dados e apresentação dos resultados" (MAINARDES, 2018, p. 7). Já em relação ao aspecto teórico, contribui para uma sociologia da ação social, em que os atores são colocados no centro do processo de implementação das políticas, não como meros implementadores, mas com capacidade de interpretação e de tradução de políticas que, muitas vezes, são pensadas para escolas ideais que não existem na prática e apresenta novos elementos para a mesma.

A partir desse conjunto teórico-metodológico (política como texto e discurso, abordagem dos ciclos de políticas ${ }^{8}$ e teoria da atuação) e ancorado por outros autores, como Foucault,

\footnotetext{
${ }^{8}$ Mainardes, um dos principais pesquisadores brasileiros a utilizar os pressupostos teórico-metodológicos de Ball, no Brasil apresenta as principais críticas e justificativas do autor sobre a abordagem do ciclo de politicas: i- a não centralização da análise política na ação estatal - para Ball nenhuma análise de política educacional pode desconsiderar o Estado, entretanto, não devem ficar restritas ao controle estatal, pois existem interpretações e tradições da política no âmbito do micro (local), que devem ser investigadas e consideradas nas análises políticas; iinão ter uma teoria do Estado impossibilita uma análise da relação entre a política educacional e a economia - a proposta do ciclo de política busca as investigações em outros atores, conflitos, resistências, etc., que apenas ficar na relação marxista centrada no Estado que, muitas vezes, pode ser estática e determinista; iii- a exclusão de outros atores das políticas - as suas análises ficam restritas a alguns atores como: políticos, administradores, professores e pais (esses sendo muitas vezes chamados de consumidores ou clientes da políticas educacionais), mas e/ou outros
} 
Bourdieu, Bernstien, entre outros, Ball se utiliza desse cabedal para analisar as reformas do Estado, a partir dos anos 1980, como a crise do Estado de Bem-Estar Social, o avanço da política neoliberal e da globalização, que atingem o sistema educacional mundial, em uma perspectiva de mercantilização. De suas pesquisas, também participam diversos colaboradores, que procuram analisar as reformas neoliberais e as políticas educacionais em diversas partes do mundo, entre essas o Brasil.

Para Ball (2014, p. 24), nesse processo de construção (ou mesmo consolidação) do discurso da política neoliberal, são estabelecidas tecnologias, entre essas o gerencialismo e a performatividade, que têm contribuído para a difusão do discurso do "[...] fim da educação pública em sua(s) forma(s) de "bem-estar"'. A seguir serão apresentadas as características dessas duas tecnologias.

\section{Gerencialismo e Performatividade}

O gerencialismo, de acordo com vários autores (LIMA; GANDIN, 2008; CLARKE; NEWMAN, 2012; HYPOLITO, 2008, 2011;), tem sua origem na crise do Estado de Bem-Estar Social $^{9}$ e na crise do modelo produtivo fordista, ocorridas no final dos anos 1970, em especial, na Inglaterra e nos Estados Unidos da América (EUA), posteriormente, essas ideias se expandem para os demais países europeus. Naquele período, o mundo atravessava profundas mudanças políticas, econômicas e sociais: a Guerra do Vietnã; crises do petróleo; avanço das economias japonesa e alemã; a contracultura; os movimentos de liberdade sexual, entre outras (HOBSBAWN, 1995).

Essas mudanças colocaram em dúvida os avanços proporcionados pelo Estado de BemEstar Social, instalado nos países europeus e nos EUA do pós-guerra (1945-1970). Entre seus questionadores estavam os representantes da Nova Direita ${ }^{10}$, que defendiam ideias conservadoras e neoliberais e alegavam que esse modelo de Estado "estava privilegiando apenas as minorias, as

atores que estão nos níveis intermediários do aparato escolar ; iv- não abordou questões de gênero e de raça - porém quando se pensa nos efeitos de segunda ordem, ou seja, justiça social, acesso e oportunidades sociais, possibilita pensar em análises voltadas para grupos específicos. Ver Mainardes (2006, 2007, 2018); Tello; Mainardes (2012).

${ }^{9}$ O Estado de Bem-Estar Social é assim caracterizado por Boaventura Santos: “[...] é a forma política dominante de países centrais na fase de capitalismo organizado, constituindo, por isso, parte integrante do modo de regulação fordista. Baseia-se em quatro elementos estruturais: um pasto entre capital e o trabalho sob a égide do Estado, com o objetivo fundamental de compatibilizar capitalismo e democracia; uma relação constante, mesmo que tensa, entre acumulação e legitimação; um elevado nível de despesas em investimentos e consumos sociais; e uma estrutura administrativa consciente de que os direitos sociais são direitos dos cidadãos e não produtos da benevolência estatal" (SANTOS, 1993 apud AFONSO, 2009, p. 101).

10 A Nova Direita organiza-se nos EUA e na Inglaterra, nos anos de 1970, com a crise do Estado de Bem-Estar Social, suas ideias foram sintetizadas por Afonso, a partir dos textos de Roger Dale e Janne Ozga "nova direita expressão genericamente utilizada para dar conta de uma grande variedade de ideias e de valores, de raiz neoconservadora e neoliberal, relativamente contraditórios. As ideias econômicas do liberalismo e do neoliberalismo valorizam, sobretudo, o mercado e a liberdade de escolha dos indivíduos, defendendo a diminuição da interferência do Estado na vida privada; consequentemente, as críticas do neoliberalismo ao Estado-providencia assentam no pressuposto de que os indivíduos conhecem melhor do que o Estado o que é bom para eles, acreditando que o mercado é não só uma instituição mais justa e eficiente para a distribuição dos bens e serviços (incluindo os que tradicionalmente são função do Estado), como também que a desigualdade entre os indivíduos e os grupos é uma característica natural da sociedade. Por outro lado, [...] a dimensão conservadora da nova direita sublinha a importância da ordem, dos valores tradicionais e da hierarquia social. Desse modo, os neoconservadores não se opõem à ação do Estado, mas apenas aos efeitos das políticas sociais que tendem a enfraquecer a inciativa individual ou a responsabilidade da família, bem como a pôr em causa a prioridade da autoridade e da ordem social. Ao mesmo tempo em que contestam os efeitos do Estado-providencia, os conservadores veem o Estado como único baluarte contra a permissividade e a erosão dos valores sociais e morais tradicionais” (AFONSO, 2009, p. 73). 
quais tiveram conquistas importantes em termos de igualdade e de direitos sociais" (LIMA; GANDIN, 2008, p. 71). Assim, em oposição a esse modelo de Estado de Bem-Estar Social, passou a ser difundido um discurso de "uma direita econômica que se opunha ao intervencionismo e pregava a desregulamentação, a descentralização e a privatização" (LESSARD; CARPENTIER, 2016, p. 29).

Além da crise do Estado de Bem-Estar Social, outras mudanças vinham ocorrendo no campo econômico e contribuíram para o avanço do discurso neoliberal e da necessidade de reestruturação do Estado. A saber:

i) globalização da economia (com nova divisão internacional do trabalho; integração de economias nacionais; acordos comerciais; mercados comuns); ii) emergência de novas relações comerciais e acordos entre nações, entre classes e grupos/setores sociais, e emergência de novas áreas (setores de serviço e informação mais importantes do que setores industriais); iii) aumento da internacionalização do comércio (capacidade de conectar mercados e movimentar capitais através de fronteiras); iv) reestruturação do mercado de trabalho (remuneração por trabalho realizado, dilapidação do poder dos sindicatos, relaxamento da legislação trabalhista); v) diminuição dos conflitos capital-trabalho, principalmente, por causa do desemprego e do subemprego, intensificação da competição e diminuição das taxas de lucro; vi) mudança de um rígido modelo fordista de produção para um modelo baseado na flexibilidade da produção (envolvendo flexibilidade no uso da força de trabalho, processo de trabalho e mercado de trabalho), redução dos custos e velocidade crescente de transferência de produtos e de informação de um lugar para outro; vii) surgimento de novas forças de produção (mudança de um modelo industrial-mecânico para um modelo baseado em microeletrônica, robótica, etc); viii) desenvolvimento da produção intensiva do capital (com resultados significativos de desqualificação de amplos setores da força de trabalho, o que conduz a um mercado de trabalho polarizado - pequenos setores altamente especializados, bem pagos, e uma grande massa bastante desqualificada, com baixos salários); ix) aumento do número de trabalhadoras mulheres e do trabalho por hora; $x$ ) aumento do setor de serviços; xi) aumento do abismo financeiro, tecnológico e cultural entre os países desenvolvidos e menos desenvolvidos (HYPÓLITO, 2008, p. 64-65).

Todas essas mudanças na esfera econômica resultaram, no campo político, em "ideias de desengajamento do Estado, redução das despesas públicas e dos déficits e privatizações dos serviços públicos" (LESSARD; CARPENTIER, 2016, p. 30), e, consequentemente, o Estado ${ }^{11}$ passa a ter uma nova configuração, a partir dos anos 1980, ou seja, o:

\footnotetext{
${ }^{11}$ Ressalta-se que esse processo de redefinição do papel do Estado atrelado às ideias neoliberais, à lógica do mercado e de Estado mínimo, descrito aqui, tem seu início na Inglaterra no final de 1970, com o Governo de Margareth Thatcher (1979 a 1990) e nos EUA, com o Governo de Ronald Reagan (1981 a 1989). Entretanto, essas ideias de reformulação também chegaram tardiamente ao Brasil, a partir de 1990, e não se pode dizer que se teve o mesmo processo, principalmente, porque nunca houve aqui um Estado de Bem-Estar Social. Independentemente desse fato, houve aqui políticas de reformulação, de reestruturação e de enxugamento do Estado, com a adoção dos princípios da Nova Gestão Pública, adotada no Brasil a partir do Governo FHC (1995 a 2002), estendendo-se pelos dois Governos de Luiz Inácio Lula da Silva (2003 a 2010) (ABRÚCIO, 2011; SILVA; CARVALHO, 2014).
} 
[...] Estado passa a funcionar com os valores do mercado, o que provoca modificações no seu papel [...] o Estado passa a não ser mais o fornecedor de serviços, mas a ter principalmente um papel de gerenciador das políticas. Ocorrem, de forma simultânea, um encolhimento do estado e um alargamento de responsabilidades da sociedade civil. O Estado passa, então, a ter um novo tipo de administração: o gerencialismo (LIMA; GANDIN, 2008, p. 72).

Nessa nova rediscussão do papel do Estado, vai ganhando força a lógica empresarial e gerencialista, para a administração dos serviços públicos, que é:

[...] uma ideologia que legitimava direitos ao poder, especialmente ao direito de gerir, construídos como necessários para alcançar maior eficiência na busca de objetivos organizacionais e sociais. Em segundo lugar, o gerencialismo é uma estrutura calculista que organiza o conhecimento sobre as metas organizacionais e os meios para alcançá-las. Usualmente está estruturado em torno de um cálculo interno de eficiência (entradas-saídas) e um cálculo externo de posicionamento competitivo em um campo de relações de mercado. Contudo, o gerencialismo também é uma série de discursos superpostos que articulam proposições diferentes até mesmo conflitantes - a respeito de como gerir e do que deve ser gerido. Assim, diferentes formas de gerencialismo enfocam liderança, estratégia, qualidade e assim por diante para produzirem um campo complexo e mutante de conhecimento gerencial. (CLARKE; NEWMAN, 2012, p. 359, destaques do autor).

Essa necessidade da relação do serviço público caracterizado por princípios da produtividade, da eficiência e da qualidade, estabelece um novo padrão para o serviço público, denominado de nova gestão pública (new public management), que pode ser sintetizado nos seguintes princípios, segundo Lesard (2016, p. 116):

- Posicionar o "cliente" no centro da ação do Estado e, portanto, romper com a lógica do administrado.

- Descentralizar as competências para o mais perto possível do campo prático.

- Responsabilizar os agentes do Estado através de prestação de contas à coletividade.

- Dar ênfase à qualidade dos serviços produzidos e à eficácia da ação pública.

- Substituir o controle procedural tradicional por uma avaliação em função dos resultados.

Esses princípios do gerencialismo, em síntese, significam que o serviço público, na figura do seu agente público, tem que buscar todos os mecanismos para "satisfazer" as necessidades individuais do cliente (cidadão), para que esse serviço seja prestado com eficiência, efetividade, produtividade e qualidade. Para garantir que estão sendo cumpridos esses princípios são adotadas políticas de controle e de monitoramento, que servem de base apara avaliar o desempenho dos seus agentes e do serviço prestado (prestação de contas). Assim, tem-se a transformação do cidadão em um consumidor individualista e "as distinções entre serviço público e troca comercial estavam sendo apagadas” (BALL, 2001b, p. 134).

Para Ball (2012, p. 38), o gerencialismo é uma tecnologia política com "a distribuição calculada de técnicas e artefatos para organizar forças e capacidades humanas em redes operacionais e funcionais de poder [...] que quando empregadas em conjunto, essas tecnologias oferecem uma alternativa eficaz e politicamente atraente [...] as tecnologias mais antigas do 
profissionalismo e da burocracia”, que são identificadas no Estado de Bem-Estar Social. Ball entende que se tem um novo gerencialismo, pois essa técnica não atinge apenas as estruturas "burocráticas do Estado", mas também a própria subjetividade do indivíduo.

O novo gerencialismo significa o desmonte dos regimes organizacionais na autonomia da profissão e sua substituição por regimes baseados no mercado. $\mathrm{O}$ novo gerencialismo também envolve novas formas de envolvimento dos empregados, particularmente, através da cultura empresarial, na qual os gerentes buscam delinear, normalizar e instrumentalizar a conduta das pessoas, a fim de alcançar os objetivos que eles postulam desejáveis. Esses desenvolvimentos são profundamente paradoxais. Por um lado, eles representam um distanciamento dos métodos tayloristas de controle, baseados em uma atitude de pouca confiança relativamente aos empregados. As responsabilidades gerenciais são delegadas e a iniciativa e a solução de problemas são altamente valorizadas. Por outro lado, novas formas de vigilância e autocontrole são instituídas como, por exemplo, sistemas de avaliação, estabelecimento de objetivos e comparações do produto (BALL, 2001b, p. 128).

Dessa forma, o novo gerencialismo não está restrito apenas às mudanças burocráticas ou de desregulamentação, mas sim ao estabelecimento de novos "processos de controle de reregulação; representam não propriamente o abandono por parte do Estado dos seus mecanismos de controle, mas sim o estabelecimento de uma nova forma de controle" (BALL, 2001a, p. 104). Esses novos mecanismos de controle são estabelecidos a distância, pois, agora, a prestação de contas ocorre "tanto no nível hierárquico, quanto perante os usuários, clientes e parceiros da instituição" (BROADFOOT, 2000, p. 55 apud LESSARD; CARPENTIER, 2016, p. 117).

Atuando em conjunto com o gerencialismo, Ball (2012, p. 37) acrescenta outra tecnologia, utilizada nas reformas do Estado de Bem-Estar Social, que é a performatividade e se utiliza das ideias de Lyotard para a definição de performatividade:

É uma tecnologia, uma cultura e um modo de regulação que emprega avaliações, comparações e demonstrações como meios de controle, desgaste e mudança. As performances de indivíduos ou organizações servem como medidas de produtividade ou resultado, demonstrações de "qualidade" [...] Ela é alcançada através da construção e publicação de informações, indicadores e outros desempenhos institucionais e de materiais promocionais como mecanismos para animar, avaliar e comparar profissionais em termos de resultados, a unidade (de medida) para nomear, diferenciar e classificar - como, por exemplo, através do "padrão de excelência" (destaques do original).

A performatividade "trabalha de fora para dentro e dentro para fora" (BALL, 2010a, p. 40), ou seja, a tecnologia da performance consegue criar mecanismos de competição para as instituições e para os indivíduos em duas direções: externamente, quando são estabelecidas metas, padrões, desempenhos, resultados que todos devem atingir, como, por exemplo, em um sistema de avaliação em larga escala, os padrões ou metas são exigidos extra escola; e, internamente, há uma cobrança direta aos indivíduos para garantir esses resultados: professores devem evitar se ausentar, verificação do conteúdo que será trabalhado; etc. Essa cobrança interna pode resultar em "sentimentos individuais de orgulho, de culpa, de vergonha e de inveja - que têm uma dimensão emocional (status), assim como (a aparência de) racionalidade e objetividade" (BALL, 2010a, p. 40).

Assim, a performatividade cria fabricações "que são versões de uma organização (ou pessoa) que não existe [...] elas são produzidas propositadamente para serem responsabilizadas (BALL, 2010a, p. 44). O que importa, na cultura da performatividade, é quanto se produz, quanto 
se é capaz de realizar, de ser eficiente, etc. Então, são criadas essas fabricações da própria organização, ou do sujeito, isto é, precisa-se criar uma imagem produtiva e eficiente das pessoas, ou das instituições às quais essas pertencem, ou as instituições. Assim, essa cultura acaba "encorajando "as escolas e universidades a fabricarem a si mesmas - a gerenciar e manipular suas performances de maneiras específicas" (BALL, 2010a, p. 45), ou seja, "vender" o que essas instituições têm de melhor, como descreve Ball (2010a, p. 45-46):

Certamente as escolas se tornaram muito mais conscientes e atentas à necessidade de organizar os modos dos quais elas se apresentam aos seus atuais e futuros pais e mães através de publicações promocionais, eventos, produções escolares, reuniões para conhecer a escola, websites e cobertura de imprensa.

Quando Ball diz que essas fabricações criam mecanismos para que organizações ou indivíduos "sejam responsabilizados", não é uma garantia de responsabilização, pois os próprios interessados (organizações ou indivíduos) é que selecionam e divulgam os dados. Dessa forma, essas fabricações contribuem justamente para desmitificar a ideia de que as "[...] tecnologias e cálculos que se apresentam como meios para tornar as organizações do setor público mais transparentes podem, na verdade, torná-las mais opacas" (BALL, 2010a, p. 45). Na mesma direção, "[...] essa onda de publicidade maciça e de (pseudo) informação também contribui para a opacidade mais do que para a transparência" (BALL, 2010a, p. 46).

Além disso, a performatividade não afeta apenas as estruturas organizacionais, mas também as subjetividades dos indivíduos, como os professores, conforme descrito por Ball (2002b, p. 6):

Os professores são representados e encorajados a refletir sobre si próprios como indivíduos que fazem cálculos sobre si próprios, "acrescentam valor a si próprios", aumentam a sua produtividade, vivem uma existência baseada em cálculos. São "sujeitos empresários", que vivem as suas vidas como "uma empresa do seu EU" - como "profissionais neoliberais" (destaques do original).

Compreende-se, então, que o gerencialismo e a performatividade são tecnologias que caminham juntas para atingir essa subjetividade do indivíduo, pois o "trabalho do gestor envolve a infusão de atitudes e de culturas, nas quais os/as trabalhadores/as se sentem eles/as próprios/as responsabilizados/as e, simultaneamente, comprometidos/as ou pessoalmente envolvidos/as na organização" (BALL, 2001a, p. 108-109). Mais adiante, Ball (2001a, p. 109) conclui que "através do cultivo da cultura empresarial os gestores procuram delinear, normalizar e instrumentalizar a conduta das pessoas de forma a atingirem os fins que elas postulam como desejáveis".

A ação direta da cultura da performatividade, na subjetividade do trabalho do professor (entende-se que possa se estender a outras categorias profissionais), é chamada, por Ball, de terrores da performatividade, em que a cultura do desempenho, dos números e da comparação é determinante do que se é e do que se faz. Essas mudanças requerem um novo tipo de professor que: 
[...] pode maximizar a sua performance, que pode descartar princípios irrelevantes, ou compromissos sociais fora de moda, para quem a excelência e a melhoria são o motor propulsor de sua prática.[...] neste aspecto há uma possibilidade real de que as relações sociais autênticas sejam substituídas por relações performativas, em que as pessoas são valorizadas somente pela sua produtividade. $\mathrm{O}$ valor delas como pessoa está erradicado. $\mathrm{O}$ mesmo pode ocorrer nas relações professor-aluno, em que os desempenhos dos alunos são vistos, principalmente, em termos de seu impacto sobre a reputação institucional (BALL, 2012, p. 44- 45).

Com isso, a cultura da performatividade funciona melhor quando é capaz de "penetrar" a mente dos indivíduos, ou seja:

[...] quando nós aplicamos em nós mesmos, quando assumimos a responsabilidade de trabalharmos de maneira mais esforçada, rápida e melhor, "melhorando" nosso "produto", como parte da nossa autoavaliação e valorização dos outros [...] De fato, a performatividade opera melhor quando conseguimos querer para nós mesmos aquilo que querem de nos [...] é como transforma o indivíduo em uma empresa, uma unidade produtiva de automaximização operando em um mercado de desempenhos - comprometida com a acirrada busca por relevância definida pelo mercado. (BALL, 2010b, p. 487 , destaques do original).

Ball destaca que o gerencialismo e a performatividade são "as irmãs feias da reforma" que "são definidas pelos estados de performance e perfeição, que nunca podem ser alcançados, pela ilusão, que sempre se afasta, de um fim para mudar. Elas são amargas, implacáveis, incansáveis e impossíveis de se satisfazer" (BALL, 2012, p. 39). Isso quer dizer que as duas tecnologias trabalham conjuntamente e que o indivíduo, por mais eficiente e produtivo que seja, nunca alcançará a excelência, pois os padrões, as metas e os resultados serão sempre alterados e nunca alcançados.

Diante dessa impossibilidade de satisfazer a cultura da performatividade, Ball apresenta como os principais efeitos dessa tecnologia nos sistemas educacionais:

O efeito de primeira ordem da performatividade é o de reorientar as atividades pedagógicas e acadêmicas, favorecendo aquelas com maior probabilidade de terem um impacto positivo mensurável em resultados de desempenho de grupos, instituições e, cada vez mais, nações e, portanto, desviando a atenção dos aspectos de desenvolvimento social emocional ou moral, os quais não têm nenhum efeito imediato mensurável no valor do desempenho. [...] um efeito de segunda ordem é que para muitos professores isso modifica a forma como eles vivenciam seu trabalho e as satisfações que obtêm dele - seu sentido de propósito moral e responsabilidade pelos seus alunos é distorcido. A prática pode passar a ser percebida como inautêntica e alienante. Compromissos são sacrificados em favor da impressão. Mas a força e a lógica da performatividade são difíceis de evitar. Evitá-las pode significar desapontar a nós mesmos, aos nossos colegas e à nossa instituição. Estruturas sociais e relações sociais são substituídas por estruturas informacionais. E há um conjunto específico de habilidades a serem adquiridas nesta situação - habilidades de apresentação e exagero, fazendo o melhor de nós mesmos, nos tornando um espetáculo. A conclusão é que nos tornamos calculáveis ao invés de memoráveis. Uma mercantilização do profissional público (BALL, 2010b, 487-488, grifos nossos). 
Observados esses efeitos da performatividade, compreende-se que essa tecnologia, aliada ao gerencialismo, produz uma concepção de educação para o mercado que impossibilita "[...] discursos metafísicos para a relação da prática a princípios filosóficos como justiça social e igualdade", ou discursos de "[...] uma educação democrática são marginalizados" (BALL, 2010b, p. 44).

\section{Considerações finais}

Entende-se que essas duas tecnologias, gerencialismo e performatividade, estiveram (e têm) influenciando a política educacional brasileira desde os anos 1990, em virtude da globalização, que proporcionou um processo de "bricolagem" das políticas, que é:

[...] um constante processo de empréstimo e cópia de fragmentos e partes de ideias de outros contextos, de uso e melhoria das abordagens locais já tentadas e testadas, de teorias canibalizadoras, e de investigação, de adoção e tendências e modas e, por vezes, de investimento em tudo aquilo que possa vir a funcionar. A maior parte das políticas são frágeis, produto de acordos, crivadas de nuances e moduladas através de complexos processos de influência, produção e disseminação de textos e, em última análise, recriadas nos contextos da prática (BALL, 2001a, p. 102).

Esse processo de "bricolagem" na política educacional brasileira pode ser observado pela influência cada vez maior das ideias estabelecidas por Organismos Internacionais, como BM e OCDE (SHIROMA; MOARES; EVANGELISTA, 2011), que introduziram ideias no processo de reestruturação do Estado, em que a gestão pública passou a ser pautada por uma "gestão de resultados", caracterizada por "uma visão centrada no desempenho [que] gerou uma prática orientada mais por metas, indicadores, monitoramento e avaliação das políticas públicas" (ABRÚCIO, 2011, p. 122).

Por fim, compreende-se que os pressupostos teórico-metodológicos desenvolvidos por Ball, desde o início dos anos 1990, mesmo centrados nos cenários educacionais, inglês e europeu, são atuais e podem auxiliar e contribuir para a análise da política educacional brasileira. Como se destaca neste texto, as políticas públicas atuais resultam da bricolagem dos diferentes modelos adotados pelo mundo globalizado, que repercutem em um modelo de sociedade das fabricações e do espetáculo (BALL, 2002b, 2010a).

\section{Referências}

ABRÚCIO, F. L. Três agendas, seus resultados e um desafio: balanço recente da administração pública federal brasileira. Desigualdade \& diversidade, Rio de Janeiro, edição especial, p. 119142, dez. 2011.

ADRIÃO, T.; PERONI, V. M. V. Consequências da atuação do Instituto Ayrton Senna para a gestão da educação pública: observações sobre 10 estudos de caso. In: Práxis Educativa, Ponta Grossa, v. 6, n. 1, p. 45-53, jan./jun. 2011. DOI: https://doi.org/10.5212/praxeduc.v.6i1.0004

AFONSO, A. J. Avaliação educacional: regulação e emancipação. São Paulo: Cortez, 2009.

AVELAR, M. Entrevista com Stephen J. Ball: uma análise de sua contribuição para a pesquisa em política educacional. Archivos Analíticos de políticas educativas, v. 24, n. 24, p. 1-14, 2016. DOI: https://doi.org/10.1590/s0101-73302009000100015 
BALL, S. J. Education reform: a critical and post-structural approach. Buckingham: Open University Press, 1994.

BALL, S. J. Diretrizes políticas globais e relações políticas locais em educação. Currículo sem Fronteiras, v. 1, n. 2, p. 99-116, jul./dez. 2001a.

BALL, S. J. Cidadania global, consumo e política educacional. In: SILVA, L. H. da. A escola cidadã no contexto da globalização. Petrópolis: Vozes, 2001b. p. 121-135.

BALL, S. J. Textos, discursos y trayectorias de la política: la teoría estratégica. Páginas - Revista de la Escuela de Ciencias de la Educación, n. 2-3, p. 19-33, 2002a.

BALL, S. J. Reformar escolas/reformar professores e os terrores da performatividade. Revista Portuguesa de Educação, v. 15, n. 2, p. 3- 23, 2002 b.

BALL, S. J. Performatividade, privatização e o pós-Estado do bem-estar. Educação \& Sociedade, Campinas, v. 25, n. 89, p. 1.105-1.126, set./dez. 2004. DOI: https://doi.org/10.1590/s0101-73302004000400002

BALL, S. J. Sociologia das políticas educacionais e pesquisa crítico-social: uma revisão pessoal das políticas educacionais e da pesquisa em política educacional. Currículo sem Fronteiras, v. 6, n. 2, p. 10-32, 2006.

BALL, S. J. Performatividades e fabricações na economia educacional: rumo a uma sociedade performativa. Educação \& Realidade, Porto Alegre, v. 35, n. 2, p. 37-55, 2010a.

BALL, S. J. Vozes/redes políticas e um currículo neoliberal global. Espaço do Currículo, v. 3, n. 1, p. 485-498, mar./set. 2010b.

BALL, S. J. Reforma educacional como barbárie social: economismo e o fim da autenticidade. Práxis Educativa, Ponta Grossa, v. 7, n. 1, p. 33-52, jan./jun. 2012. DOI: http://10.5212/PraxEduc.v.7i1.0002

BALL, S. J. et al. A constituição da subjetividade docente no Brasil: um contexto global. Educação em Questão, Natal, v. 46, n. 32, p. 9-32, maio/ago. 2013.

BALL, S. J. Educação Global S.A.: novas redes políticas e o imaginário neoliberal. Ponta Grossa: UEPG, 2014.

BALL, S. J. What is policy? 21 years later: Reflections on the possibilities of policy research. Discourse: Studies in the cultural politics of education, v. 36, n. 3, p. 306-313, 2015. DOI: https://doi.org/10.1080/01596306.2015.1015279

BALL, S. J.; MAGUIRE, M.; BRAUN, A. How schools do policy: policy enactments in secondary schools. London: Routledge, 2012.

BALL, S. J.; MAGUIRE, M.; BRAUN, A. Como as escolas fazem as políticas: atuação em escolas secundárias. Ponta Grossa: Editora UEPG, 2016.

BALL, S. J.; YOUDELL, D. Privatización encubierta en la educación pública. In: $\mathrm{V}$ CONGRESO MUNDIAL INTERNACIONAL DE LA EDUCACIÓN. 5., 2007, Bruselas. Anais... Bruselas, 2007. 
BOWE, R.; BALL, S.; GOLD. A. Reforming education \& changing schools: case studies in policy sociology. London: Routledge, 1992.

CHARLOT, B. Educação e globalização: uma tentativa de colocar ordem no debate. Sísifo. Revista de Ciências da Educação, Lisboa, v. 4, n. 4, p. 129-136, out./dez. 2007.

CLARKE, J.; NEWMAN, J. Gerencialismo. Educação \& Realidade, Porto Alegre, v. 37, n. 2, p. 353-381, 2012. DOI: https://doi.org/10.1590/s2175-62362012000200003

FREY, K. Políticas públicas: um debate conceitual e reflexões referentes à prática da análise de políticas públicas no Brasil. Planejamento e Políticas Públicas, n. 21, p. 211-259, jun. 2000.

GAWRYSZEWSKI, B.; MOTTTA, V. C. da; PUTZKE, C. K. Gestão privada de escolas públicas da Educação Básica: um novo mercado sob a tutela do Estado. Práxis Educativa, Ponta Grossa, v. 12, n. 3, p. 728-748, set./dez. 2017. DOI: https://doi.org/10.5212/praxeduc.v.12i3.003

GENTILI, P. A. A.; SILVA, T. T. da. Neoliberalismo, qualidade total e educação. Petrópolis, RJ: Vozes, 2001.

HOBSBAWN, E. A era dos extremos. São Paulo: Companhia das Letras, 1995.

HOSTINS, R. C. L.; ROCHADEL, O. Contribuições de Stephen Ball para o campo das políticas educacionais. Revista on line de Política e Gestão Educacional, Araraquara, v. 23, n. 1, p. 61-84, jan./abr., 2019. DOI: https://doi.org/10.22633/rpge.v23i1.11947

HYPÓLITO, Á. M. Estado gerencial, reestruturação educativa e gestão da educação. Revista Brasileira de Política e Administração da Educação, v. 24, n. 1, p. jan./abr. 2008.

HYPÓLITO, Á. M. Reorganização gerencialista da escola e trabalho docente. Educação: teoria e prática, Rio Claro, v. 21, n. 38, p. 59-78, 2011.

JOSLIN, M. F. A. Reseña de libro: Ball, S. J.; Maguire, M.; Braun, A. Como as escolas fazem as políticas: atuação em escolas secundárias. Tradução de Janete Bridon. Ponta Grossa: Editora UEPG, 2016. 220 p. Revista de Estudios Teóricos y Epistemológicos en Política Educativa, v. 2, p. 1-8, 2017. DOI: https://doi.org/10.5212/retepe.v.2.011

LESSARD, C.; CARPENTIER, A. Políticas educativas: a aplicação na prática. Editora Vozes Ltda., 2016.

LIMA, I. G. de; GANDIN, L. A. Entendendo o estado gerencial e sua relação com a educação: algumas ferramentas de análise. Práxis Educativa, Ponta Grossa, v. 7, n. 1, p. 69-84, jan./jun. 2012. DOI: $\underline{\text { http://10.5212/PraxEduc.v.711.0004 }}$

LIMA, L. F.; SOUZA, B. S.; LUCE, M. B. A abordagem do ciclo de políticas nos Programas de Pós-Graduação brasileiros: um mapa das teses e dissertações. Revista de Estudios Teóricos y Epistemológicos en Política Educativa, Ponta Grossa, v. 3, p. 1-29, 2018. DOI: https://doi.org/10.5212/retepe.v.3.008

MAINARDES, J. Abordagem do ciclo de políticas: uma contribuição para a análise de políticas educacionais. Educação \& Sociedade, Campinas, v. 27, n. 94, p. 47-69, jan./abr. 2006. DOI: https://doi.org/10.1590/s0101-73302006000100003

MAINARDES, J. Reinterpretando os ciclos de aprendizagem. São Paulo: Cortez, 2007. 
MAINARDES, J. Entrevista com o Professor Stephen J. Ball. Olh@ res, Guarulhos, v. 3, n. 2, p. $161-171,2015$.

MAINARDES, J. A abordagem do ciclo de políticas: explorando alguns desafios da sua utilização no campo da Política Educacional. Jornal de Políticas Educacionais, Curitiba, v. 12, n. 16, p. 1-19, ago. 2018. DOI: https://doi.org/10.5380/ipe.v12i0.59217

MAINARDES, J.; GANDIN, L. A. A abordagem do ciclo de políticas como epistemetodologia: usos no Brasil e contribuições para a pesquisa sobre políticas educacionais. In: TELLO, C.; ALMEIDA, M. L. P. (Org.). Estudos epistemológicos no campo da pesquisa em Política Educacional. Campinas: Mercado de Letras, 2013a. p. 143-167.

MAINARDES, J.; GANDIN, L. A. Contributions of Stephen J. Ball to the research on educational and curriculum policies in Brazil. London Review of Education, v. 11, n. 3, p. 256264, nov. 2013b. DOI: https://doi.org/10.1080/14748460.2013.840985

MAINARDES, J.; MARCONDES, M. I. Entrevista com Stephen J. Ball: um diálogo sobre justiça social, pesquisa e política educacional. Educação \& Sociedade, Campinas, v. 30, n. 106, p. 303-318, jan./abr. 2009. DOI: https://doi.org/10.1590/s0101-73302009000100015

MAINARDES, J.; STREMEL, S. Informações sobre a abordagem do ciclo de políticas. Ponta Grossa: UEPG, 2015. Disponível em: <www.uepg.br/gppepe>. Acesso em: 9 abr. 2018.

MARCONDES, M. I.; FREUND, C.; LEITE, V. F. Resenha: Como as escolas fazem as políticas: atuação em escolas secundárias. Práxis Educativa, Ponta Grossa, v. 12, n. 3, p. 10281034, set./dez. 2017. DOI: https://doi.org/10.5212/praxeduc.v.12i3.019

MARTINS, E. M. Movimento Todos pela Educação: um projeto de nação para a educação brasileira. 2013. 184 f. Dissertação (Mestrado em Educação) - Faculdade de Educação, Universidade Estadual de Campinas, Campinas, 2013.

OLIVEIRA, A. de; LOPES, A. C. A abordagem do ciclo de políticas: uma leitura pela teoria do discurso. Cadernos de Educação, Pelotas, n. 38, p. 19-41, jan./abr. 2011. DOI: http://dx.doi.org/10.15210/caduc.v0i38.154

OLIVEIRA, S. B. de. A assessoria privada de gestão educacional na rede municipal de ensino de Campinas. Educação: teoria e debate, São Paulo, v. 26, n. 53, p. 628-649, set./dez. 2016. DOI: https://doi.org/10.18675/1981-8106.vol26.n53.p628-649

PAVEZI, M. Contribuições da teoria da atuação: análise a partir de uma pesquisa sobre políticas de Educação Especial no contexto da prática. Revista de Estudios Teóricos y Epistemológicos en Política Educativa, Ponta Grossa, v. 3, p. 1-19, 2018. DOI: https://doi.org/10.5212/retepe.v.3.009

ROSA, S. S. da. Uma introdução às ideias e às contribuições de Stephen J. Ball para o tema da implementação de políticas educacionais. Revista de Estudios Teóricos y Epistemológicos en Política Educativa, Ponta Grossa, v. 4, p. 1-17, 2019. DOI: https://10.5212/retepe.v.4.004

SERAFIM, M. P.; DIAS, R. de. B. Análise de política: uma revisão da literatura. Cadernos Gestão Social, v. 3, n. 1, p. 121-134, jan./jun. 2012.

SHIROMA, E. O.; CAMPOS, R. F.; GARCIA, R. M. C. Decifrar textos para compreender a política: subsídios teórico-metodológicos para análise de documentos. Perspectiva, Florianópolis, v. 23, n. 2, p. 427-446, 2005. 
ShIROMA, E. O.; MORAES, M. C. M. de; EVANGELISTA, O. Política educacional. 4. ed. Rio de Janeiro: Lamparina, 2011.

SILVA, M. A. da. Qualidade social da educação pública: algumas aproximações. Cadernos Cedes, Campinas, v. 29, n. 78, p. 216-226, maio/ago. 2009. DOI: https://doi.org/10.1590/s0101-32622009000200005

SILVA, M. S. P.; CARVALHO, L. S. Faces do gerencialismo em educação no contexto da nova gestão pública. Educação em Questão, Natal, v. 50, n. 36, p. 211-239, set./dez. 2014.

TELLO, C.; MAINARDES, J. La posición epistemológica de los investigadores en política educativa: debates teóricos en torno a las perspectivas neomarxista, pluralista y posestructuralista. Archivos Analíticos Políticas Educativas, v. 20, n. 9, p. 3-31, mar. 2012. DOI: https://doi.org/10.14507/epaa.v20n9.2012

\section{Mauricio de Sousa}

Doutor em Educação pela Unicamp. Pesquisador Loed/Unicamp. Supervisor escolar, Rede Municipal de São Paulo-SP. 